\title{
Modeling of Directional Solidification of Columnar Grain Structure in CMSX-4 Nickel-Based Superalloy Castings
}

\author{
D. Szeliga, K. Kubiak, A. Burbelko, M. Motyka, and J. Sieniawski
}

(Submitted July 23, 2013; in revised form November 26, 2013; published online December 18, 2013)

\begin{abstract}
The paper presents the analysis of numerical simulation of the Bridgman directional solidification process performed on CMSX-4 rods. The numerical simulation was studied applying the ProCAST software. The constitutive law parameters of the normal Gaussian distribution were used to describe the nucleation process. The coefficients of the equation were determined and used to calculate the growth rate of dendrite tip. The analysis of the as-cast microstructure was carried out with the use of Aphelion software in order to determine the average area of grains and their quantity. The experimental verification of both nucleation and grain growth coefficients used for the simulation of the directional solidification process confirmed that the model was correct and described well the investigated process of directional solidification using the Bridgman method.
\end{abstract}

Keywords CMSX-4, coefficients of nucleation and grain growth, directional solidification, numerical simulation, ProCAST

\section{Introduction}

The tendencies in the development of turbine aircraft engines aim at the improvement of economical factors such as the reduction of the specific-fuel consumption and the specific-thrust (power). It is mainly related to the increase of temperature of exhaust gases before the turbine and the rise of air flow rate in the engine as well as the increase of compression ratio in the engine compressor (Ref 1). The performance and development of turbine aircraft engines and industrial gas turbines strongly require new materials, like nickel- and cobalt-based superalloys, which reveal the exceptional combination of high temperature strength, toughness, and resistance to degradation in the corrosive and oxidizing environment. The maximum temperature of exhaust gases at the turbine inlet depends on the material properties used in the production of the rotor blades of high pressure turbine (Ref 2$)$.

A further improvement of aircraft engine performance is possible through the development of manufacture processes of aircraft engine hot-section components. Hence, parallel to the introduction of new types of nickel-based superalloys, the research on manufacturing technology of the directionally solidified castings has been conducted. Such a technique was

D. Szeliga, K. Kubiak, M. Motyka, and J. Sieniawski, Department of Materials Science, Faculty of Mechanical Engineering and Aeronautics, Rzeszów University of Technology, 2, Wincentego Pola Str., 35-959 Rzeszów, Poland; and Research and Development Laboratory for Aerospace Materials, 4, Żwirki i Wigury Str., 35-959 Rzeszów, Poland; and A. Burbelko, Faculty of Foundry Engineering, AGH University of Science and Technology, 23, Reymonta Str., 30-059 Krakow, Poland. Contact e-mail: dszeliga@prz.edu.pl. used mainly to obtain aircraft engine hot-section components and industrial gas turbine blades (Ref 3 ).

During the process of directional solidification with the Bridgman method, a specific amount of liquid metal is poured into a heated ceramic mold placed in the furnace. After filling up the ceramic shell mold with the liquid alloy, the casting is withdrawn from the heater zone at a defined velocity to the cooled area of the furnace (Ref 4 )

The ProCAST is a software tool enabling the insight into natural behavior of parameters of the process such as alloy flow and turbulence during filling, cooling, and directional solidification. One of its modules - the CAFE (Cellular Automaton Finite Element)_-was particularly useful in conducting the numerical analysis with the cellular automata method (CA) (Ref 5, 6). The differential equations, which describe the temperature field and characterize the flow of liquid metal, were solved with the finite element method (FEM). The simulation of the grain nucleation and growth process, combined with the influence of temperature field, was based on the calculations performed using the CA method. A finite element mesh was generated in the whole volume of the geometric model, while in the area of microstructure modeling an additional, regular CA mesh was formed.

The CAFE module, implemented in the ProCAST software, allowed the prediction of morphology (shape and size) and quantity of equiaxed grains in the casting (Ref 7) as well as the relation between the equiaxed and columnar layers in the ingot (Ref 8). It was introduced for the simulation of the directional solidification process of castings manufactured with the use of the Bridgman (Ref 9) and LMC (liquid metal cooling) methods (Ref 10). The ProCAST software helped to reduce the number of experiments necessary to perform the verification of the casting process at the stage of design, development, and implementation of technology.

\section{The Modeling of Nucleation and Grain Growth}

The numerical simulation of grain nucleation and growth was carried out using the CAFE module (ProCAST software). 
The dependence of grain quantity on undercooling degree of the liquid metal below the liquidus temperature was taken into account applying the normal distribution (Fig. 1) (Ref 5):

$\frac{d n}{d(\Delta T)}=\frac{n_{\max }}{\Delta T_{\sigma} \cdot \sqrt{2 \pi}} \exp \left[-\frac{1}{2}\left(\frac{\Delta T-\Delta T_{N}}{\Delta T_{\sigma}}\right)^{2}\right]$,

where $\Delta T$-current value of undercooling $(\mathrm{K}), \Delta T_{\mathrm{N}}$-mean value of Gaussian distribution $(\mathrm{K}), \Delta T_{\sigma}$-mean value of undercooling (Gaussian distribution) $(\mathrm{K})$, and $n_{\max }$-maximum number of substrata which enable the grain nucleation (surface nucleation, $\mathrm{m}^{-2}$; bulk nucleation, $\mathrm{m}^{-3}$ ).

The increase of the undercooling degree of liquid metal (Eq 1) affects the quantity of grains. New grains nucleate on the walls of ceramic shell mold and on the exogenous substrata in the bulk of liquid metal. The CAFE module allows specifying the sets of parameters used in Eq 1 separately for the volumetric nucleation and surface nucleation (including differentiation for selected walls).

In the performed simulation of the directional solidification process, it was assumed that no new grains along the height of the rod casting appeared. Hence, the bulk nucleation was neglected. The surface nucleation of grains was assumed only for the contact area of the casting base and the chill plate.

The quantity of grains and their shape determined in the numerical simulation depend on the value of coefficients in Eq 1. It was difficult to establish the correct value of the surface nucleation coefficient. The analysis of experimental research and numerical simulation, performed for different values of nucleation coefficients, was a base for its determination. The numerical simulation was carried out for the assumed parameter values $\Delta T_{\sigma}, \Delta T_{\mathrm{N}}$, and the maximum quantity of grains $n_{\max }$ presented in Table 1 .

The continuous grain growth during the solidification process is caused by the undercooling of liquid metal. According to the KGT model (Kurz-Giovanola-Trivedi) (Ref 12), the rate of growth of the dendrite tip is controlled by the undercooling degree, in accordance with the equation:

$v(\Delta T)=a_{2} \cdot \Delta T^{2}+a_{3} \cdot \Delta T^{3}$.

The formula (Eq 2) was implemented in the CAFE module. The values of parameters $a_{2}$ and $a_{3}$ in Eq 2 were established for

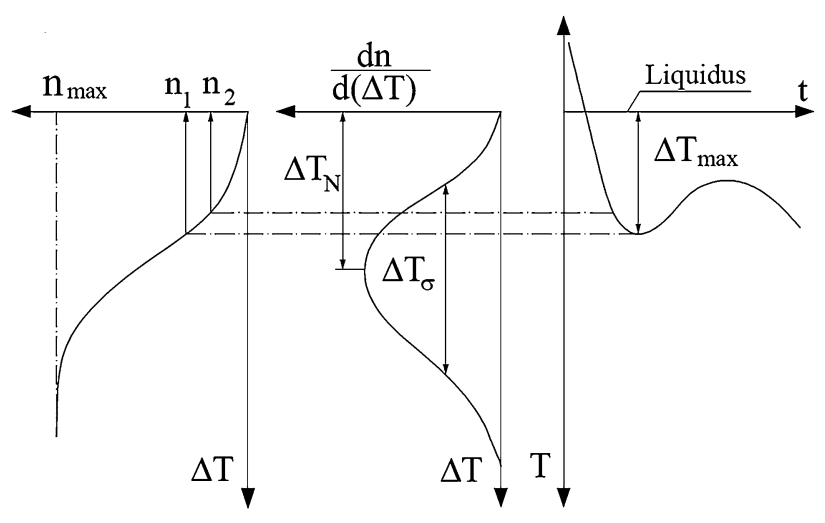

(a)

(b)

(c)

Fig. 1 The influence of undercooling degree of liquid metal on the nuclei quantity (a), the growth of nuclei quantity with undercooling increment (normal distribution) (b) and the cooling curve (c) (Ref 11) the applied KGT model, while taking into account the properties of the analyzed alloy.

The chemical composition of CMSX-4 nickel superalloy and the binary phase diagrams $\mathrm{Ni}-\mathrm{X}(\mathrm{X}$ - the component of CMSX-4 alloy) were used to determine the alloying elements, depending on temperature. The values of distribution coefficient $k$ and liquidus slope $m$ were calculated for the binary Ni-X alloy. The calculated values of distribution coefficient and liquidus slope are presented in Table 2.

The grain growth coefficients $a_{2}$ and $a_{3}$ were calculated using the CAFE module (ProCAST software) (Table 1). The obtained values were as follow: $a_{2}=3.149^{-7} \mathrm{~m} \mathrm{~s}^{-1} \mathrm{~K}^{-2}$ and $a_{3}=4.257^{-7} \mathrm{~m} \mathrm{~s}^{-1} \mathrm{~K}^{-3}$. The rate of dendrite growth controlled by undercooling was determined in that way (Fig. 2).

Additionally, the following values of parameters characterizing the solidification process were applied (Ref 15): capillary length $\Gamma=3.65 \times 10^{-7} \mathrm{~K} \mathrm{~m}$, diffusion coefficient of the elements in liquid metal $D_{1}=3.6 \times 10^{-9} \mathrm{~m}^{2} \mathrm{~s}^{-1}$.

\section{Research Methodology}

\subsection{The Numerical Simulation}

The numerical simulation of the directional solidification process of castings in the shape of rods was carried out in order to establish the influence of process parameters on the shape and size of columnar grains in the cast samples.

The three-dimensional geometric model of wax assembly, shell mold, and furnace chamber were designed. The wax assembly consisted of eight rod castings (diameter- $12.5 \mathrm{~mm}$, length $-243 \mathrm{~mm}$ ), gating system, pouring cup, and chill plate.

The temperature distribution was established in four areas of the casting, at the distance of 21, 39, 58, and $102 \mathrm{~mm}$ from the casting base (Fig. 3a). While developing the geometric models of the heating chamber, which consisted of two heaters with $300 \mathrm{~mm}$ diameter, and the thermal insulation; the authors took the actual size of vacuum furnace into account and used it in the Bridgman method (Fig. 3b). The finite element mesh used during the calculations also covered the internal surface of the melting chamber and the cooling chamber of the furnace (Fig. 3c).

The developed geometric description of the assembly and the three-dimensional environment of the ceramic shell mold (heating chamber) was imported to the MeshCAST module. The 3-D finite element mesh for gating system, castings (without the ceramic shell mold), and the model of heating chamber was generated using the module. That was used as a basis for creating the layered mesh of ceramic shell mold with

Table 1 The superimposed values of nucleation parameters

Parameters of nucleation

\begin{tabular}{lcc}
\cline { 2 - 3 } Grains quantity $\boldsymbol{n}_{\mathbf{m a x}}, \mathbf{m}^{-\mathbf{2}}$ & $\boldsymbol{\Delta \boldsymbol { T } _ { \boldsymbol { \sigma } } , \mathbf { K }}$ & $\boldsymbol{\Delta} \boldsymbol{T}_{\mathbf{N}}, \mathbf{K}$ \\
\hline $10^{7}$ & 0.3 & 0.5 \\
\multirow{2}{*}{$5 \times 10^{7}$} & 0.1 & 0.5 \\
\multirow{2}{*}{$10^{8}$} & 0.3 & 0.5 \\
& 0.1 & 0.5 \\
& 0.3 & 0.5 \\
& 0.1 & 0.5 \\
\hline
\end{tabular}


the thickness of $10 \mathrm{~mm}$. The 2-D finite element mesh was generated as the enclosure (the inner surfaces of melting- and cooling chamber).

Table 2 The value of distribution coefficient and the slope of liquidus line for the CMSX-4 nickel superalloy

\begin{tabular}{lccl}
\hline $\begin{array}{l}\text { Alloying } \\
\text { element }\end{array}$ & $\begin{array}{c}\text { Content of } \\
\text { element } \boldsymbol{c}_{\mathbf{i}} \text {, wt.\% }\end{array}$ & $\begin{array}{c}\text { Distribution } \\
\text { coefficient, } \boldsymbol{k}_{\mathbf{i}}\end{array}$ & $\begin{array}{c}\text { Slope } \\
\text { value } \boldsymbol{m}_{\mathbf{i}}\end{array}$ \\
\hline K wt. \\
Ni-Cr (Ref 10) & 6.5 & 0.6 & -1.9 \\
Ni-Co (Ref 10) & 9 & 1 & -0.4 \\
Ni-Mo (Ref 10) & 0.6 & 1 & -0.001 \\
Ni-W (Ref 10) & 6 & 1 & -2.4 \\
Ni-Ta (Ref 13) & 6.5 & 0.25 & -2 \\
Ni-Ti (Ref 14) & 1 & 0.5 & -11.5 \\
Ni-Al (Ref 14) & 5.6 & 0.6 & -4 \\
Ni-Re (Ref 13) & 3 & 0.2 & -7.25 \\
\hline
\end{tabular}

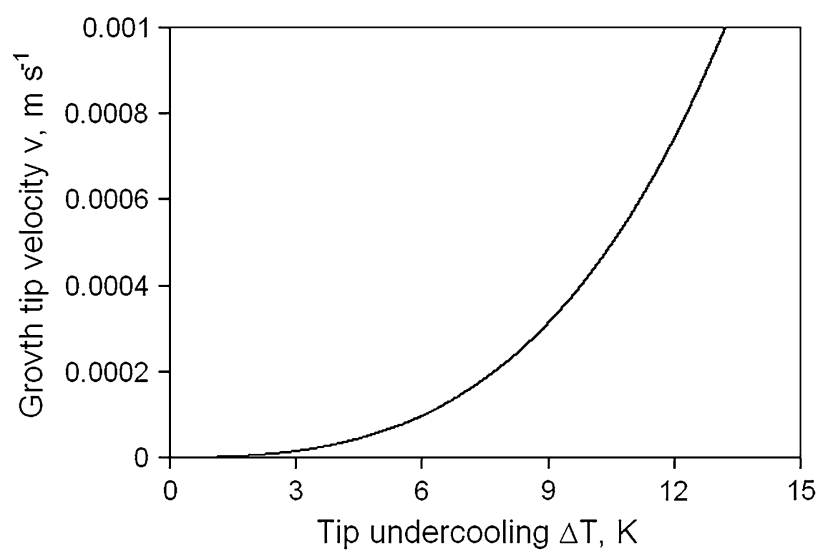

Fig. 2 The influence of liquid alloy undercooling on growth rate of dendrite tip
Modeling of the casting solidification processes required establishing the boundary conditions, which reflected the actual heat transfer process. Since the directional solidification process was conducted in vacuum, it was assumed that the heat exchange inside the furnace chamber occurred through radiation. Therefore, the first-type boundary conditions were applied (temperature value) for the enclosure and the heaters. The emissivity $(\varepsilon)$ values were assumed for:

- heater surface, thermal insulation and thermal baffle (graphite) $\varepsilon=0.8$,

- the material of ceramic shell mold $\varepsilon=0.7$,

- the surface of chill ring $\varepsilon=0.7$,

- the internal surface of three-dimensional ambient (water cooling jacket of the furnace) $\varepsilon=0.6$ and the temperature of $293 \mathrm{~K}$.

The heat transfer from the inner surface of the chill plate and the water chill ring was described by the boundary conditions of the third-type. The values of heat transfer coefficient $h=2500 \mathrm{~W} \mathrm{~m}^{-2} \mathrm{~K}^{-1}$ and water temperature $293 \mathrm{~K}$ were used, due to the intensive water cooling of those surfaces.

The contact thermal resistance of the materials is of large significance for the heat transfer rate between them. This phenomenon is described by the characteristic boundary conditions of the fourth-type. Within the developed model the authors established those boundary conditions for the contact surface of ceramic shell mold and casting as well as for the casting and the chill plate $\left[h=20 \mathrm{~W} \mathrm{~m}^{-2} \mathrm{~K}^{-1}\right.$ (Ref 14)]. The same boundary conditions were also used for the thermal insulation boundary inside the furnace $\left(h=200 \mathrm{~W} \mathrm{~m}^{-2} \mathrm{~K}^{-1}\right)$.

The thermophysical parameters of the CMSX-4 nickel superalloy were chosen for the models of rod castings and the gating system performed in the ProCAST module.

The assumptions concerning the suitable boundary conditions and thermophysical parameters of the alloy and the ceramic shell mold as well as the remaining materials were precisely described in Ref $16,17$.

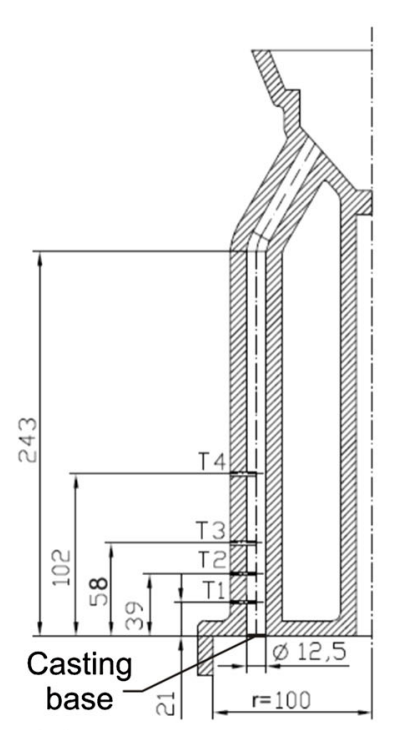

(a)

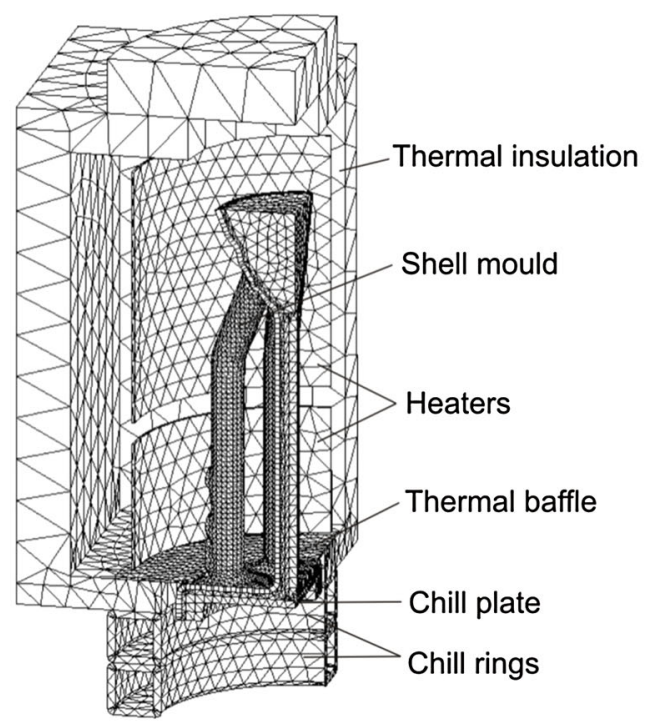

(b)

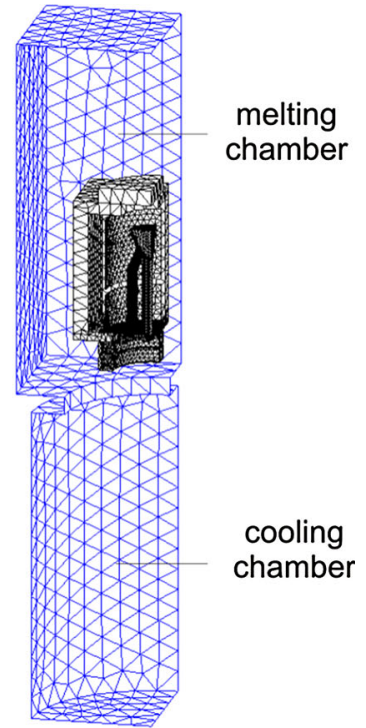

(c)

Fig. 3 The location of points of predicted temperature measurement, at different distances from the casting base (a) and the finite elements mesh of heating chamber (b) as well as inner surface of the melting chamber and the cooling chamber of the furnace (c) 


\subsection{Experimental Castings}

The rods were cast in the directional solidification process. The temperature measurement of the casting was executed during the solidification and its further cooling process. The obtained results were used for the verification of imposed boundary conditions, the calculated nucleation coefficients, and grain growth rates in the casting. It was assumed that the temperature distribution and the solidification process of columnar grains were similar in each rod of the assembly. It was ensured due to the cylindrical shape of graphite heaters and symmetric location of models in the assembly. Hence, the temperature was measured in four points of the rod, at the distance of $21,39,58$, and $102 \mathrm{~mm}$ from the casting base (Fig. 4a). To control temperature, B type thermocouples (PtRh30-PtRh6) of the $0.2 \mathrm{~mm}$ diameter were applied.

The wax assembly was used for manufacturing the multilayer ceramic shell mold. After the application of 12 layers, the ceramic shell mold wall was approximately $10 \mathrm{~mm}$ thick (Fig. 4b).

The directional solidification process of rods made of CMSX-4 nickel superalloy was performed using the Bridgman method in the VIM 2 E-DS/SC vacuum furnace manufactured by ALD Vacuum Technologies GmbH. The furnace belongs to the equipment of the Research and Development Laboratory for Aerospace Materials at Rzeszów University of Technology. The $4 \mathrm{~kg}$ charge was inductively melted under vacuum. The ceramic shell mold was placed on the chill plate and preheated

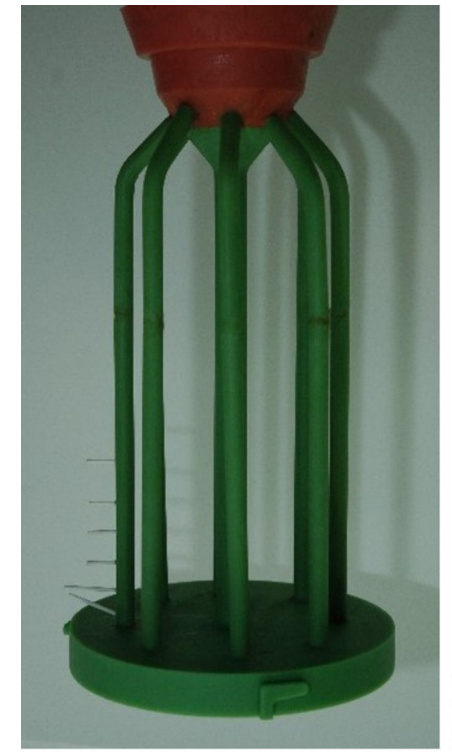

(a)

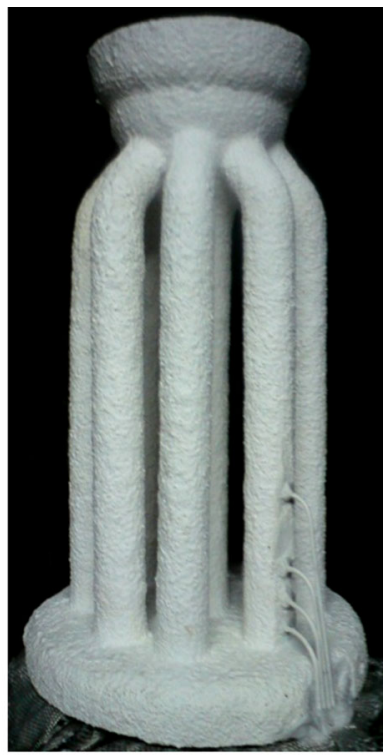

(b)
Fig. 4 The wax assembly (a) and the ceramic shell mold-view with thermocouples (b)

Table 3 The chemical composition of the CMSX-4 nickel superalloy

Elements content, wt.\%

\begin{tabular}{lcccccccc}
\hline Cr & Co & Mo & Al & Ti & Ta & Hf & Re & Ni \\
\hline 6.5 & 9.0 & 0.6 & 5.6 & 1.0 & 6.5 & 0.1 & 3.0 & Rest
\end{tabular}

in the furnace up to a temperature of $1793 \mathrm{~K}$, at which the mold was filled up with the CMSX-4 nickel superalloy of the same temperature (Table 3). It was next withdrawn from the heating space to the cooled area of the furnace at velocity $v_{\mathrm{w}}=3 \mathrm{~mm} \mathrm{~min}^{-1}$.

Based on the macro- and microstructure analysis of the rod casting the experimental verification of the developed model and the numerical simulation was carried out. The simulation was performed for the directional solidification process to predict the size and quantity of grains of cast rods. Both the outer surface and the longitudinal section of the rod casting were submitted to the microstructure analysis. The microstructure was observed on the surface of rod cross-sections, at different distances from the casting base (the chill plate): 13, $21,39,58,78,102$, and $140 \mathrm{~mm}$. The surface of metallographic specimens was etched using the chemical reagent of composition: $10 \mathrm{~g} \mathrm{CuSO}_{4}+50 \mathrm{~cm}^{3} \mathrm{HCl}+50 \mathrm{~cm}^{3} \mathrm{H}_{2} \mathrm{O}$. The quantitative analysis of microstructure images was done using the Aphelion software. The number and the average area of grains were determined on cross-sections of the castings.

\section{Results and Discussion}

The analysis of numerical simulation and experimental research results were used for the verification of nucleation and grain growth rate parameters as well as boundary conditions applied during the simulation of directional solidification process performed using the Bridgman method.

\subsection{Numerical Simulations}

The results of numerical simulation made possible to establish the temperature distribution in the heating chamber of furnace, ceramic shell mold, and casting (Fig. 5). They were also used for the calculation of liquid alloy undercooling. The undercooling determined in the simulation process was applied in the CAFE module (ProCAST software) in order to simulate the grain growth of the cast alloy.

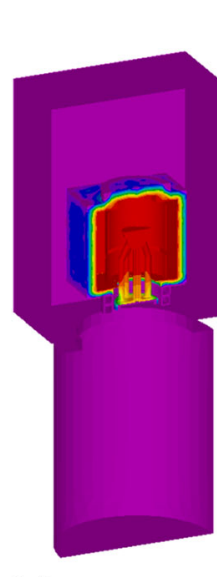

(a)

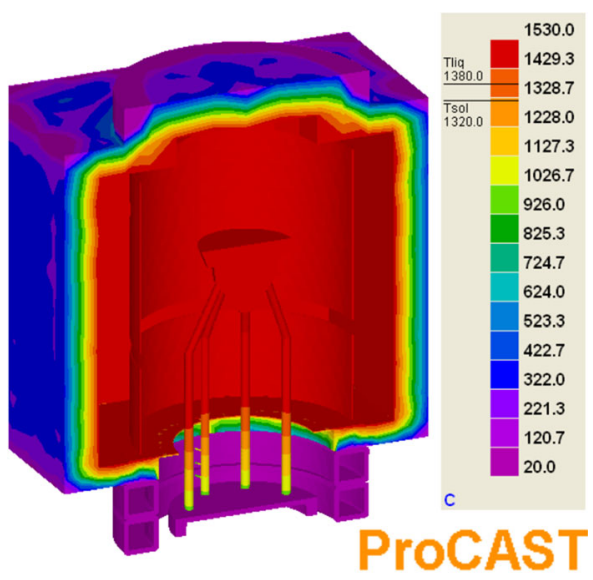

(b)
Fig. 5 The predicted temperature distribution at internal surface of the melting chamber and the cooling chamber of the furnace and shell mold (a) and the casting (b), after the withdrawal to distance $80 \mathrm{~mm}$ 


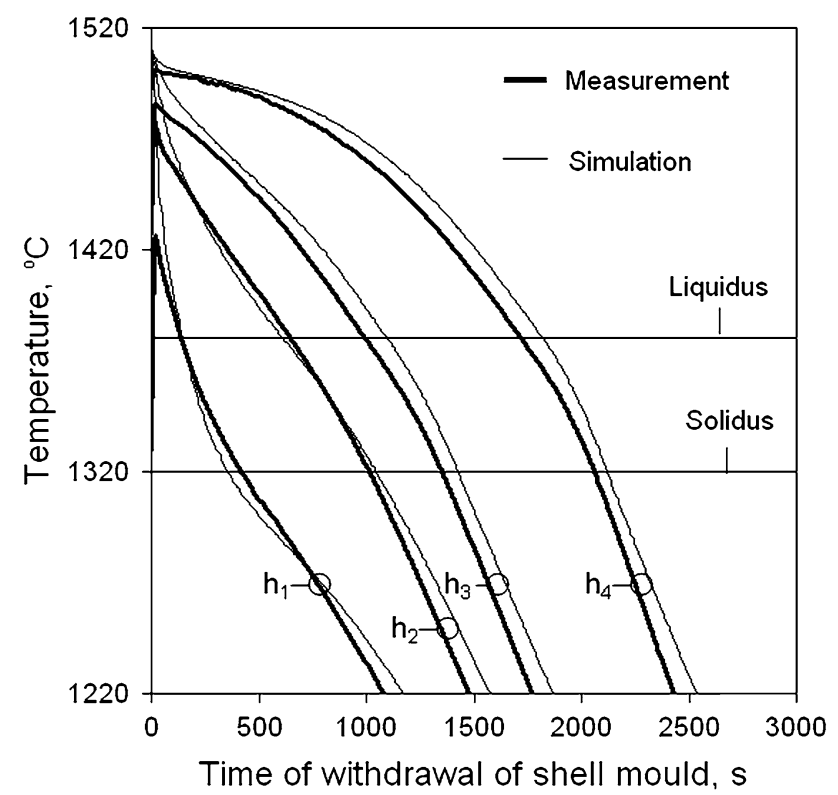

Fig. 6 The temperature distribution in dependence on time of withdrawal of the ceramic shell mold and distance from the casting base: $h_{1}-21, h_{2}-39, h_{3}-58$, and $h_{4}-102 \mathrm{~mm}$
The numerical simulation and temperature measurements in the ceramic shell mold were used in order to determine the heating time of the mold, before it was filled up with the melted alloy. They were also required to establish the influence of chill plate on the solidification process. The ceramic shell mold was placed on the chill plate in the heating chamber and was heated up to $1793 \mathrm{~K}$. During the initial stage of the heating process, the heating rate reached its highest value, decreased afterward, and became constant. A further heating of the mold caused a slight increase of its temperature.

The temperature distribution along the mold length was nonuniform. The chill plate caused underheating of the ceramic shell mold at the distance of approximately $25 \mathrm{~mm}$ from the casting base. The correct value of heat exchange coefficient between the ceramic shell mold and the chill plate was crucial for the modeling process. It caused the cooling rate of the lower part of both the mold and the casting to attain high values. The largest temperature drop of the liquid alloy occurred in the area of influence of the chill plate on the liquid alloy and the ceramic shell mold (Fig. 6). The decrease of the liquid alloy temperature in that area resulted in the formation of solidified thin layer of the alloy which was undercooled below the liquidus temperature. Nuclei and small-size-equiaxial grains formed on the surface of chill plate (Fig. 7). It contained grains of random

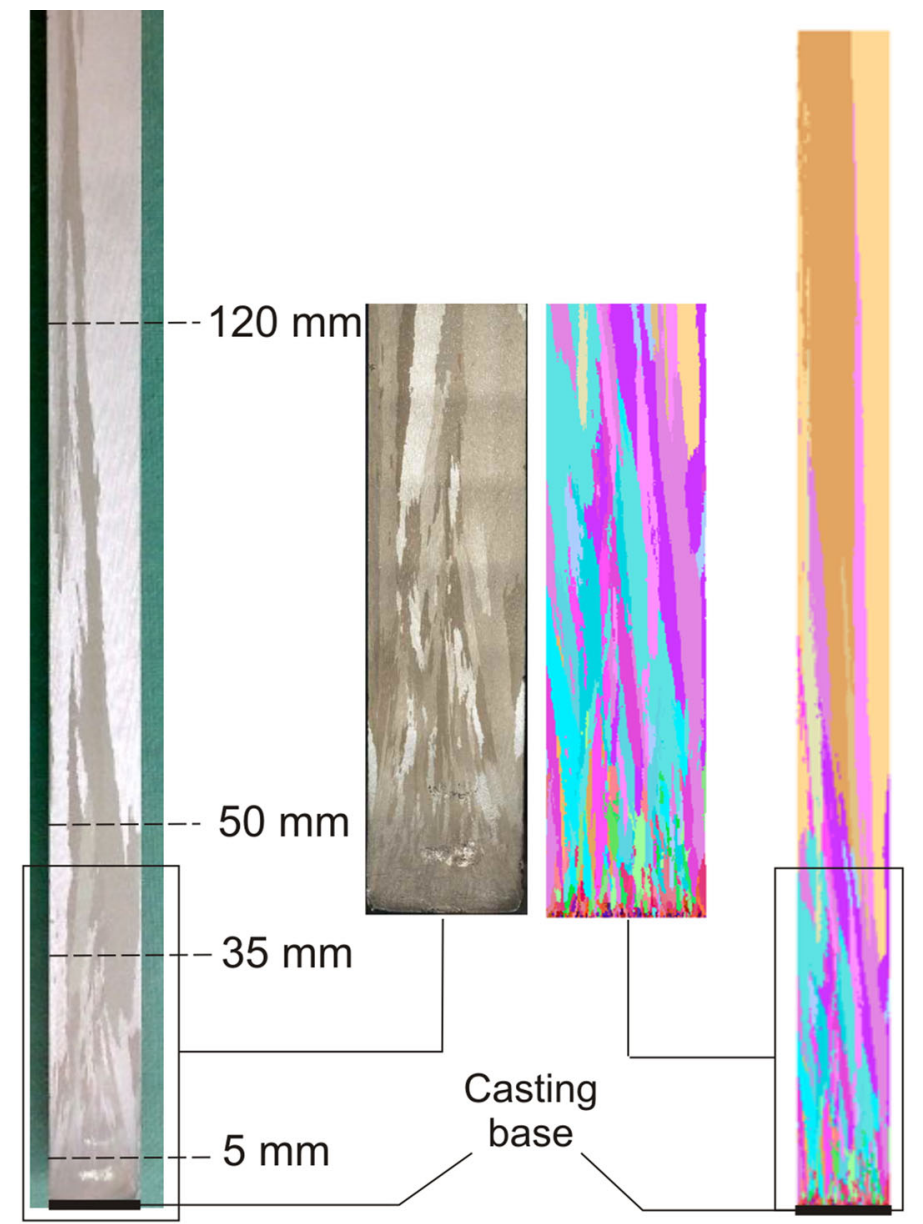

(a) (b)

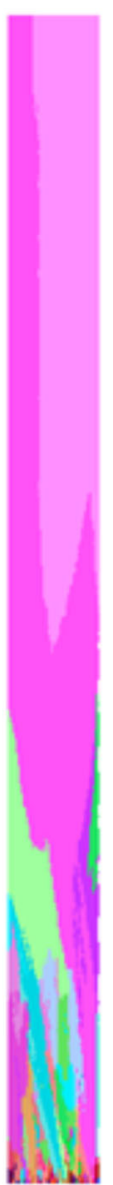

(c)
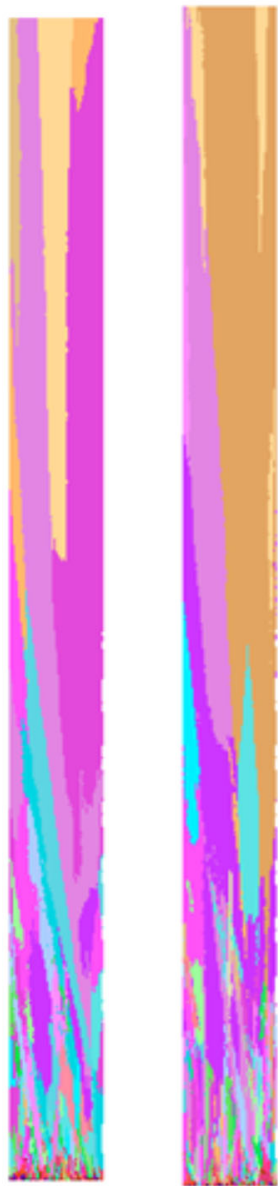

(d) (e)

Fig. 7 The macrostructure of the casting made of the CMSX-4 nickel superalloy - the longitudinal section of casting: the experimental a) and the predicted (simulated) b-e) macrostructure. The parameters of nucleation process: b) $n_{\max }=10^{8} \mathrm{~m}^{-2}, \Delta T_{\mathrm{N}}=0.5 \mathrm{~K}, \Delta T_{\sigma}=0.3 \mathrm{~K}$, c) $\left.\left.n_{\max }=10^{7} \mathrm{~m}^{-2}, \Delta T_{\mathrm{N}}=0.5 \mathrm{~K}, \Delta T_{\sigma}=0.1 \mathrm{~K}, \mathrm{~d}\right) n_{\max }=5 \times 10^{7} \mathrm{~m}^{-2}, \Delta T_{\mathrm{N}}=0.5 \mathrm{~K}, \Delta T_{\sigma}=0.3 \mathrm{~K}, \mathrm{e}\right) n_{\max }=10^{8} \mathrm{~m}^{-2}, \Delta T_{\mathrm{N}}=0.5 \mathrm{~K}, \Delta T_{\sigma}=0.1 \mathrm{~K}$ 


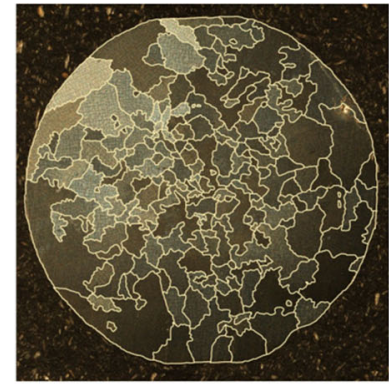

(a)

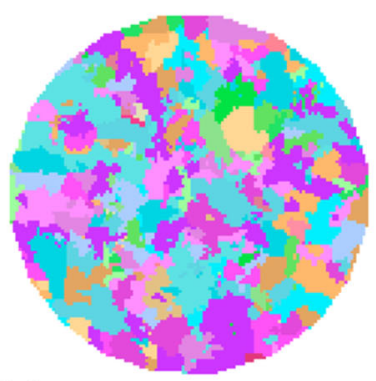

(e)

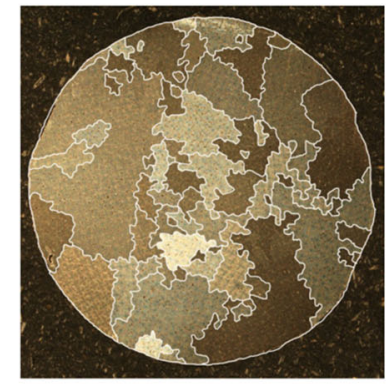

(b)

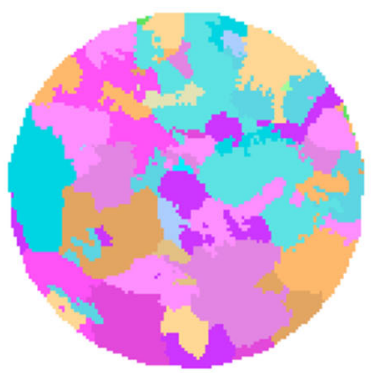

(f)

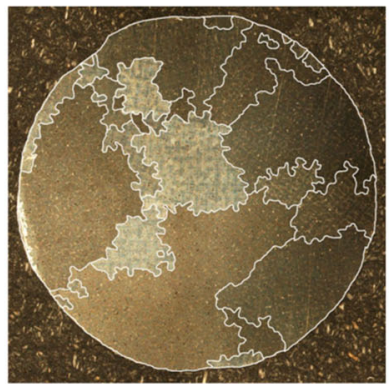

(c)

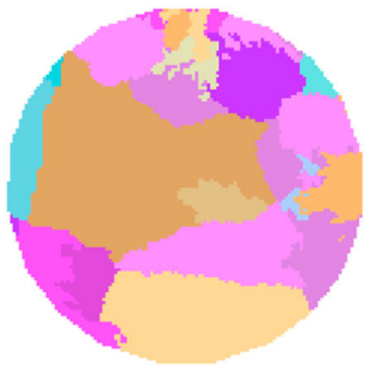

(g)

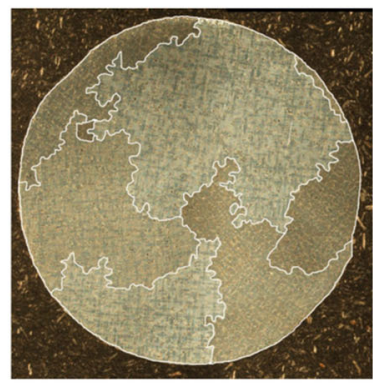

(d)

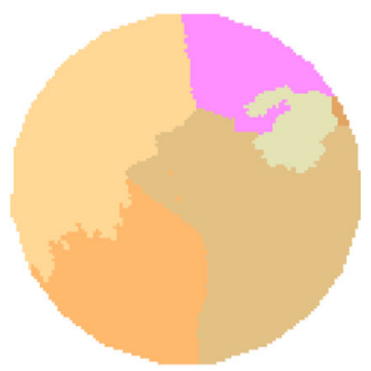

(h)

Fig.8 The true (a-d) and predicted (e-h) microstructure of rod casting base at cross-section, at distance of: a and e) $12 \mathrm{~mm}$, b and f) $40 \mathrm{~mm}$, c and g) $81 \mathrm{~mm}, \mathrm{~d}$ and h) $140 \mathrm{~mm}$

crystallographic orientation in relation to the heat flow direction.

Withdrawing the ceramic shell mold from the heating chamber of the furnace and the directional heat transfer resulted in undercooling of the next volume of liquid alloy. The dendrite arms, growing along the direction of heat flow, had the largest probability to sustain their further growth. Therefore, only a part of dendrite arms, oriented along the preferred directions, continued to grow. The dendrites without the preferred growth directions stopped to grow on the expense of columnar crystals, whose growth direction was parallel to the direction of heat flow (Fig. 7). The microscopic examination revealed that the area of the most intensive alloy undercooling (contact of the chill plate with the casting), at the beginning of the rod casting, was characterized by the highest number of grains. The number of grains decreased with a rise of the distance between the chill plate and the beginning of casting (Fig. 8).

\subsection{Experimental Observations}

The analysis of microstructure investigations performed for the cross-section of the rod casting, at the distance of $12 \mathrm{~mm}$ from its base (Fig. 8a) showed that there was a significant difference of grain size depending on distance from the external surface to the central part of the rod casting. The largest grains were located in the external near-surface zone. On the basis of the microstructure analysis of the longitudinal section of the rod, it could be concluded that grain growth under a certain angle to the axis of casting depended on distance from the casting base (Fig. 7). The highest inclination angle of grains was in the contact area of the chill plate and the casting (Fig. 7a). Their growth direction depended on heat flow and temperature gradient as well as on the curve of liquidus isotherm (Ref 10). The numerical simulation of temperature distribution and the performed experiments showed that the
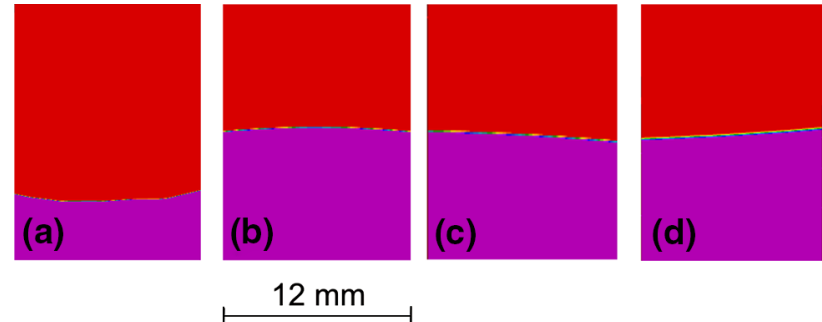

Fig. 9 The shape of liquidus isotherm at distance from the casting base: a) $5 \mathrm{~mm}$ - concave, b) $35 \mathrm{~mm}$-convex, c) $50 \mathrm{~mm}$-inclined towards the symmetry axis of the mold, d) $120 \mathrm{~mm}$ - inclined to the chill ring surface

liquidus isotherm curve was concave (Fig. 9a). Hence, the grains located near the external casting surface grew faster and they were responsible for blocking the grain growth in the central part of the casting. Above the zone affected by the chill plate, the grain growth direction was also dependent on the shape of the liquidus isotherm curve. The isotherm of convex shape was observed at the height of approximately 15 to $40 \mathrm{~mm}$ from the casting base (Fig. 9b). Then, approximately at $40 \mathrm{~mm}$ from the chill plate, the liquidus isotherm took the shape inclined towards the symmetry axis of the mold (Fig. 9c). However, after withdrawing the mold to the position denoted by the height of approximately $80 \mathrm{~mm}$, the inclination angle changed. Above that height, up to the end of the solidification process (rod casting height $-230 \mathrm{~mm}$ ), the liquidus isotherm acquired the shape inclined to the chill ring surface (Fig. 9d). For such process conditions, the tendency to block the grains, which were located on the side of chill rings, by grains growing on the opposite side of casting (central part of shell mold) could be observed. It was found that the growth of columnar grains also depended on the shape of liquidus isotherm above the area of influence of chill plate on the casting morphology (Fig. 7). 
The selection of nucleation parameters was based on the simulation results of the directional solidification process, performed for the constant value of parameter $\Delta T_{\mathrm{N}}=0.5 \mathrm{~K}$ and $\Delta T_{\sigma}=0.1$ and $0.3 \mathrm{~K}$ as well as the maximum grain quantity $n_{\max }=10^{7}, 5 \times 10^{7}$, and $10^{8} \mathrm{~m}^{-2}$ (Table 2).

The analysis of the numerical simulation and experimental research results, concerning the number and the average area of grains on the casting cross-section, allowed the determination of the best match values of nucleation coefficients during the directional solidification process of the CMSX-4 nickel superalloy (Fig. 10). It was revealed that the highest number of grains was present in the casting base. The quantity of grains decreased intensively in further casting sections, until the distance of $40 \mathrm{~mm}$ was reached. For the distances larger than $40 \mathrm{~mm}$ the grain quantity changed to a lesser extent.

The presented research results allowed establishing the proper starter height for the models of single crystal castings. The solidification process is highly related to the quantity of grains in the upper part of starter block. The basic function of starter is the formation of lowest quantity of columnar grains on the inlet of the selector, while maintaining the minimum deviation of crystallographic orientation from the [001] axis. On the basis of the analysis of calculation results and literature survey (Ref 18, 19) it has been established that application of grain starter of height exceeding $35 \mathrm{~mm}$ does not cause the significant decrease of grain quantity and the deflection angle. However, it leads to the reduction of blade casting height in the model assembly and, as a consequence, to a rise of production costs. Hence, starters with a height ranging from approximately 25 to $35 \mathrm{~mm}$ are most frequently used in industry manufacture.

It has been established that the assumed maximum quantity of nuclei $n_{\max }$ in the casting base, which is in contact with the chill plate, determines the simulated quantity and average area of grains, depending on the distance from the casting base. The remaining nucleation parameters $-\Delta T_{\mathrm{N}}$ and $\Delta T_{\sigma}$ - does not influence significantly the quantity of grains in the section, depending on the distance from the casting base. The maximum consistency of simulation results with the experimental ones was obtained for the nuclei quantity of $n_{\max }=10^{8} \mathrm{~m}^{-2}$ and $\Delta T_{\mathrm{N}}=0.5 \mathrm{~K}, \Delta T_{\sigma}=0.3 \mathrm{~K}$ (Fig. 10,11$)$.

The mechanical properties (creep resistance) of directionally solidified blades made of nickel superalloy depend on the crystallographic orientation of columnar grains. Therefore, a suitable quantity of columnar grains and minimum deviation angle from the crystallographic direction [001] should be maintained.

On the basis of the literature analysis (Ref 20), it was determined that the quantity of grain nuclei on the chill plate surface (casting base) decreases with the rise of temperature difference between the pouring temperature of melt and the nucleation temperature of alloy (called superheating temperature). The temperature increase of both ceramic shell mold and pouring, also the values of withdrawal velocity lead to the reduction of deviation angle in the area of chill plate influence on the casting (height of approximately $40 \mathrm{~mm}$ from the casting base) (Ref 20). Therefore, the grain quantity and their deviation angle along the casting height will depend on the solidification process in the area of chill plate and the heat transfer proceeding above the chill plate influence area (Fig. 7).

Based on that it was established that the further optimization of solidification process of columnar grains should be conducted for higher temperature value of ceramic shell mold and pouring, also for a higher velocity of casting withdrawal, in relation to the conducted experimental process.

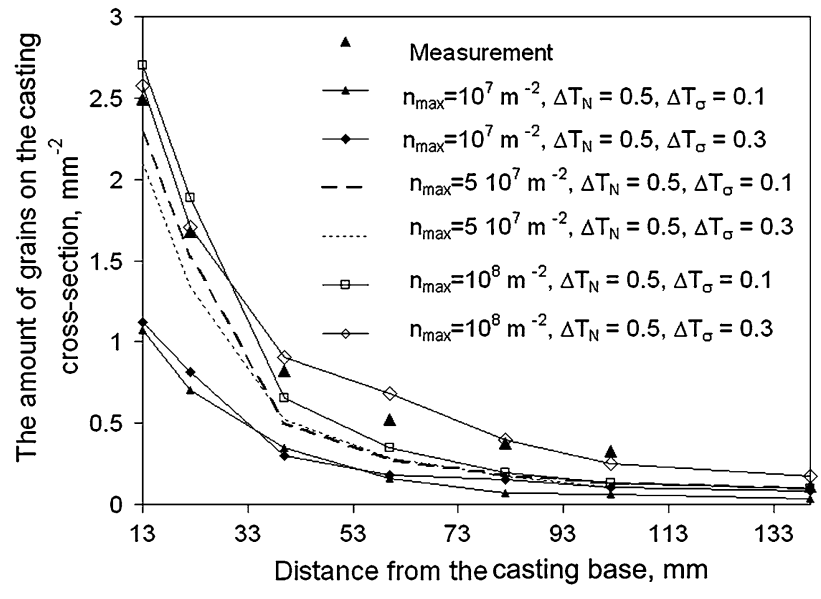

Fig. 10 The quantity of grains at casting cross-section, depending on distance from the casting base-experimental research and numerical simulation

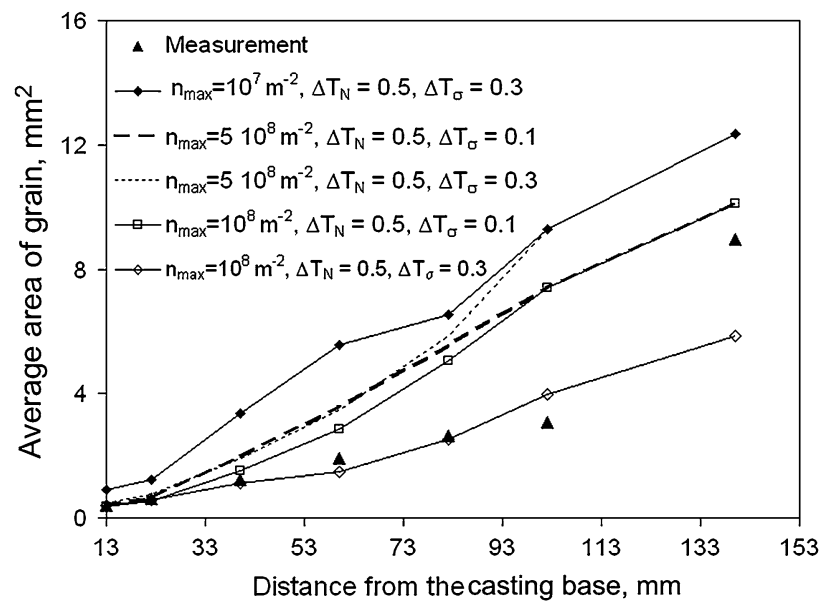

Fig. 11 The dependence of the average area of grain depending on distance from the casting base

\section{Conclusions}

The analysis of the numerical simulation and experimental research results, conducted for the directional solidification process of rod castings (CMSX-4 nickel superalloy), made possible to verify the applied boundary conditions as well as the values nucleation and grain growth rate coefficients.

It has been established that the casting cooling rate reaches its highest value in the area of influence of the chill plate on the casting and the ceramic shell mold. The increase of cooling rate leads to the rise of the undercooling value of liquid metal and the growth of grain quantity. The assumed maximum number of nuclei $\left(n_{\max }\right)$ has the largest influence on the results of the numerical simulation performed for the directional solidification process. It has been shown that the intensity of change of grain quantity is the highest in the casting section, at the distance shorter than $40 \mathrm{~mm}$ from the casting base.

It has been shown that grain growth direction depends not only on the crystallographic orientation of grains, but also on the shape of liquidus isotherm and heat flow direction. 
The obtained results of numerical simulation allow defining the block starter height of the models used for manufacturing the CMSX-4 single crystal castings.

The analysis of experimental results also indicates that the numerical simulation of directional solidification process, with the use of the KGT model, is highly consistent with the course of the actual process which was performed for the castings manufactured with the application of the Bridgman method.

\section{Acknowledgments}

The financial support of Structural Funds in the Operational Programme-Innovative Economy (IE OP) financed from the European Regional Development Fund-Project "Modern material technologies in aerospace industry," $\mathrm{Nr}$ POIG.01.01.02-00015/08-00 is gratefully acknowledged.

\section{Open Access}

This article is distributed under the terms of the Creative Commons Attribution License which permits any use, distribution, and reproduction in any medium, provided the original author(s) and the source are credited.

\section{References}

1. S. Farokhi, Aircraft Propulsion, Wiley, Hoboken, 2008, p 127-214

2. J. Sieniawski, Criteria and Methods of Evaluation of Materials for Elements of Aircraft Turbine Engines, Rzeszów University of Technology, Rzeszów, 1995, p 20-50 (in Polish)

3. C. Reed Roger, The Superalloys: Fundamentals and Applications, Cambridge University Press, Cambridge, 2006, p 121-131

4. B. Chmiela, D. Szeliga, M. Sozańska, J. Jarczyk, and J. Cwajna, Analysis of Stray Grain Formation in Single Crystal CMSX-4 Superalloy, Pract. Metallogr., 2013, 50(8), p 548-560

5. Ch.-A. Gandin and M. Rappaz, Coupled Finite Element-Cellular Automaton Model for the Prediction of Dendritic Grain Structures in Solidification Processes, Acta Metall. Mater., 1994, 42(7), p 2233-2246

6. Ch.-A. Gandin, J.-L. Desbiolles, M. Rappaz, and Ph. Thevoz, A ThreeDimensional Cellular Automaton-Finite Element Model for the
Prediction of Solidification Grain Structures, Metall. Trans. A, 1999, 30(12), p 3153-3165

7. D. Szeliga, K. Kubiak, A. Burbelko, R. Cygan, and W. Ziaja, Modelling of Grain Microstructure of IN-713C Castings, Solid State Phenom., 2013, 197, p 83-88

8. A. Burbelko, J. Falkus, W. Kapturkiewicz, K. Sołek, P. Drożdż, and M. Wróbel, Modeling of the Grain Structure Formation in the Steel Continuous Ingot by CAFE Method, Arch. Metall. Mater., 2012, 57(1), p 379-384

9. A.J. Elliott and T.M. Pollock, Thermal Analysis of the Bridgman and Liquid Metal Cooled Directional Solidification Investment Casting Processes, Metall. Mater. Trans. A, 2007, 38(4), p 871-882

10. A. Kermanpur, N. Varahram, P. Davami, and M. Rappaz, Thermal and Grain-Structure Simulation in a Land-Based Turbine Blade Directionally Solidified with the Liquid Metal Cooling Process, Metall. Mater. Trans. B, 2000, 31(6), p 1293-1304

11. Ph. Thévoz, J.L. Desbiolles, and M. Rappaz, Modeling of Equiaxed Microstructure Formation in Casting, Metall. Trans. A, 1989, 20(2), p 311-322

12. W. Kurz, B. Giovanola, and R. Trivedi, Theory of Microstructural Development During Rapid Solidification, Acta Metall., 1986, 34(5), p 823-830

13. H. Okamoto, Phase Diagrams for Binary Alloys, ASM International, Materials Park, 2010, p 653-654

14. T. Imwinkelried, Modelling of a Single Crystal Turbine Blade Process, Ph.D. Thesis, EPFL Lausanne, 1993, p 195

15. L. Nastac, Modeling and Simulation of Microstructure Evolution in Solidifying Alloys, Kluwer Academic Publishers, Boston, 2004

16. D. Szeliga, K. Kubiak, and G. Jarczyk, The Influence of the Radiation Baffle on Predicted Temperature Gradient in Single Crystal CMSX-4 Castings, Int. J. Metalcasting, 2013, 7(3), p 17-23

17. D. Szeliga, K. Kubiak, J.S. Suchy, and G. Jarczyk, Temperature Distribution in Single Crystal Casting Made of CMSX-4 Nickel Superalloy Manufactured by Bridgman Method, Mater. Eng., 2013, 191(1), p 7-12 (in Polish)

18. H.J. Dai, N. D'Souza, and H.B. Dong, Grain Selection in Spiral Selectors During Investment Casting of Single Crystal Turbine Blades: Part I. Experimental Investigation, Metall. Mater. Trans. A, 2011, 42(11), p 3430-3438

19. H.J. Dai, H.B. Dong, N. D’Souza, J.-C. Gebelin, and R.C. Reed, Grain Selection in Spiral Selectors During Investment Casting of Single Crystal Components: Part II. Numerical Modeling, Metall. Mater. Trans. A, 2011, 42(11), p 3439-3446

20. S.F. Gao, L. Liu, N. Wang, X.B. Zhao, J. Zhang, and H.Z. Fu, Grain Selection During Casting Ni-Base, Single-Crystal Cuperalloys with Spiral Grain Selector, Metall. Mater. Trans., 2012, 43(10), p 3767-3775 